\title{
Effectiveness of a mindfulness-oriented substance use prevention program for boys with mild to borderline intellectual disabilities: study protocol for a randomised controlled trial
}

\author{
Lucie Waedel ${ }^{1}$, Anne Daubmann², Antonia Zapf ${ }^{2}$ and Olaf Reis ${ }^{1 *}$ (D)
}

\begin{abstract}
Background: Boys with mild to borderline intellectual disabilities (MBID) are at particular risk to drink in harmful ways once they start to consume alcohol. Interventions based on mindfulness have been proven to be effective in preventing substance use, but mostly for adults with MBID. A mindfulness oriented intervention targeting 11-17 years old boys will be tested in a randomised controlled trial. Study aim is to investigate the benefits of this new intervention compared to an active control condition within a 12 months follow-up.

Methods: In this randomised controlled proof of concept study, 82 boys with MBID who consumed any alcohol during the last year will be randomised either to the 6 week mindfulness oriented intervention or the control group receiving a control intervention equal in dose and length. The intervention group undergoes mindfulness training combined with interactive drug education, while the control group completes a health training combined with the same education. In the intention-to-treat analysis the primary outcome is the self-reported delay of first post-intervention drunkeness within a 12 months follow-up time span, measured weekly with a short app-based questionnaire. Secondary outcome is the use of alcohol, tobacco and other drugs within 30 days post-intervention. Changes in neurobiological behavioural parameters, such as impulse control, reward anticipation, and decision making, are also investigated. Other secondary outcomes regard trait mindfulness, emotion regulation, psychopathological symptoms, peer networks, perceived stress, and quality of life. In addition, a prospective registry will be established to record specific data on the population of 11-17 year old boys with MBID without any alcohol experience.
\end{abstract}

Discussion: This study offers the opportunity to gain first evidence of the effectiveness of a mindfulness-oriented program for the prevention of substance use for boys with MBID.

Trial registration: German Clinical Trials Register, DRKS00014042. Registered on March 19th 2018.

Keywords: Mild to borderline intellectual disability, Alcohol, Prevention, Adolescents, Mindfulness, Substance use

* Correspondence: olafreis@med.uni-rostockde; olafreis@med.uni-rostockde 'Department of Child and Adolescent Psychiatry and Neurology, University Medical Centre Rostock, Gehlsheimer Str. 20, 18147 Rostock, Germany

Full list of author information is available at the end of the article

(c) The Author(s). 2020 Open Access This article is licensed under a Creative Commons Attribution 4.0 International License, which permits use, sharing, adaptation, distribution and reproduction in any medium or format, as long as you give appropriate credit to the original author(s) and the source, provide a link to the Creative Commons licence, and indicate if changes were made. The images or other third party material in this article are included in the article's Creative Commons licence, unless indicated otherwise in a credit line to the material. If material is not included in the article's Creative Commons licence and your intended use is not permitted by statutory regulation or exceeds the permitted use, you will need to obtain permission directly from the copyright holder. To view a copy of this licence, visit http://creativecommons.org/licenses/by/4.0/. The Creative Commons Public Domain Dedication waiver (http://creativecommons.org/publicdomain/zero/1.0/) applies to the data made available in this article, unless otherwise stated in a credit line to the data. 


\section{Background}

\section{Background and rationale}

Across many nations, the prevalence of alcohol consumption rises steadily from early adolescence to adulthood. As for underage drinking, a recent U.S. National Survey on Drug Use and Health (NSDUH) reported about $29.8 \%$ of 15 -year-olds who had drunk alcohol once in their life [1]. According to the European School Survey Project on Alcohol and Other Drugs (ESPAD), almost half (47\%) of 15-16-year olds reported drinking alcohol at the age of 13 or younger [2]. In numerous rankings, Germany appears as one of the countries where adolescents drink high quantities of alcohol [3]. According to data from the study on Health Behavior of School Children 2017/18 in Germany (HBSC), 8.7\% of 11-year-olds reported alcohol consumption at least once in their lives. This number goes up to one third (32.1\%) for 13-year-olds and three quarters (72.4\%) for 15-yearolds [4]. Similar increases were observed for smoking [5]. In another German study conducted by the Federal Centre for Health Education in 2018, approximately 4600 children and adolescents were surveyed, with about $1 \%$ of 14-15-year-olds reporting consumption of risky quantities. This percentage rises to almost $10 \%$ among 16-17-year-olds [6], given that $10 \mathrm{~g}$ of pure alcohol consumption for women (one standard drink) and more than $20 \mathrm{~g}$ for men (two standard drinks) are considered as risky [7]. About 14\% of 12-17-year-olds reorted at least 1 day of binge drinking in the previous 30 days (five drinks per occasion for men/ four drinks for woman) [6]. While, historically, lifetime and 30-day prevalence of alcohol consumption decreased significantly between 1995 and 2015, heavy episodic alcohol consumption stayed about this level [2]. Several studies indicate that early substance use predicts substance use later in life $[8$, 9]. In a German prospective longitudinal study, Laucht and Schmid observed that three quarters of 15-year-olds who had tried alcohol were also alcohol consumers later in life, one-fifth of them being weekly drinkers [10].

Learning to consume alcohol in a non-harming way constitutes an important developmental task of adolescence. Young people with limited intellectual abilities face even greater developmental challenges [11]. In a recent review, Van Duijvenbode \& VanDerNagel examined 138 studies on substance use among subjects with mild to borderline intellectual disabilities (MBID, IQ 50-85). For people with MBID aged between 11 and 21 years, the lifetime prevalence of alcohol consumption ranged between 15.6 and 75.4\% [12]. A study by Emerson compared drinking behaviours of adolescents with and without MBID and found lower prevalence for adolescents with MBID (41\%) compared to those without (50\%) [13]. This result resonates with our own study where we found higher prevalences of adolescents without MBID drinking (79.9\%) when compared to adolescents with MBID (63.5\%) [11]. In our study, however, we found the proportion of abstainers to be higher in pupils with MBID, which leaves a greater proportion of adolescents who are yet about to start drinking. However, a study by Pacoricona et al. found no significant differences between both groups [14]. Another study by Emerson reported slightly higher prevalence for adolescents with MBID (15.8\%), compared to $13.2 \%$ in those without MBID [15]. Contradictory results of studies comparing adolescents with and without MBID may result from methodological weaknesses, as many studies do not control for confounding factors, such drinking habits of the parents or parental education [11].

According to the 2018 NSDUH study, the lifetime prevalence of any alcohol use disorder (AUD) is about $1.6 \%$ in $12-17$ year olds of the general population in the U.S. [16]. However, in adolescents diagnosed with a MBID the lifetime prevalence rates for substance use disorders (SUD) seem to be higher as they range between $0.1-2.7 \%$ [12]. Along with our findings, authors of the review conclude that adolescents with MBID compared to age mates without MBID have a higher risk of subsequent problems, once they start consuming [11, 12]. In our study in special schools, boys with MBID, in particular, showed a significantly higher risk of consuming alcohol in a more harmful way and of becoming intoxicated once they start drinking. They also ran into conflict with the law more often and more quickly compared to their age-mates without MBID or to girls with MBID [11]. The duration between the onset of drinking and the first drunkenness was about 11 months for students without MBID and about half the time for students with MBID. Risk factors for alcohol consumption in this group were male sex [11, 17], smoking [15], having friends who use substances $[15,18]$, and the degree of cognitive impairment [12]. Boys with MBID constitute a special group since in contrast to boys with more severe impairments they have a more independent lifestyle, are more closely involved in social life, and therefore participate more in the "normal" cultural life giving them better access to substances. With increased participation, conflicts associated with social comparison and negative role models become more likely. More severe behavioural and emotional problems, such as anxiety, aggression, depression or exposure to prejudice, are assumed to be additional predictors of substance use for this group [19, 20]. Confounding factors, such as lower socio-economic status, unfavourable living conditions, low activity lifestyles, difficulties in getting in touch with peers, and negative role models are reported to be more frequent for this group [12].

Intending to address a special target group, we developed a prevention program based on mindfulness, a 
modern approach to intensify all sorts of treatment, which we combine with interactive education about addictions. It aims at the high-risk group of male adolescents with MBID, who have started drinking alcohol.

The concept of mindfulness has its historical roots 2500 years ago in the religious context of Asia [21]. Coming from this historical context, the former Zen student and professor emeritus of the University of Massachusetts Medical School, Jon Kabat-Zinn, is regarded as the pioneer who transferred mindfulness into the medical-scientific context. In 1979 he founded a clinic for stress reduction where he taught his Mindfulness Based Stressed Reduction program (MBSR) and undertook the first systematic examination [22]. Since then, mindfulness has been increasingly adopted as a psychological and therapeutic element in healthcare to reduce stress, pain and illness. Publications on the subject have grown exponentially during the last 20 years [23, 24]. In most cases, mindfulness is defined as a moment-bymoment experience with clear-eyed attention to the working of the mind, body and behaviour $[25,26]$. The regulation and maintenance of focused attention and awareness lead to an experience of wakefulness called state mindfulness $[27,28]$. Mindfulness can also be conceptualised as a stable trait assumed to be a part of the personality, which is pronounced differently in individuals and can be increased by regular practice [28]. Mindfulness means not only perceiving the current moment, but also having a non-judgmental attitude towards it. For instance, mindfulness-based approaches expand behavioural therapy programs by promoting the development of acceptance and the ability to distinguish between changeable and unchangeable conditions in order to manage and perceive everyday life in a more self-determined way. In the treatment of addiction, there is promising evidence from general populations that mindfulness-based interventions can reduce alcohol consumption, general craving and the cue-induced craving for alcohol [29, 30]. Higher trait-mindfulness is associated with lower substance use [31]. According to the meta-analysis of Dunning et al. on children and adolescents, mindfulness is positively associated with selfcontrol, executive functioning and attention, and is inversely associated with depression, anxiety/stress and negative social behaviour [32].

With the help of mindfulness, we want to strengthen individual resources for conscious decision making. We assume that the drug education program enriched by mindfulness also influences psychological and behavioural moderators of substance use. Addiction prevention programs in schools have proven to be effective when they use interactive teaching methods [33]; therefore we use interactive methods in drug education that deal with different addictions and addictive behaviour in a playful and task-oriented manner. This concept will be proven in a randomised controlled trial.

\section{Specific objectives of the study}

The study aims to provide initial evidence that mindfulness can play an important role in preventing boys with MBID from consuming alcohol, tobacco and other drugs (ATOD), with alcohol being the focus of interest. Furthermore, we like to target and evaluate the role of biobehavioural factors in improving addiction-related outcomes. The effectiveness of the intervention is evaluated in a randomised controlled trial with an active control condition and weekly follow-ups over a period of 12 months to test the following hypotheses: (1) The intervention is more effective than the active control condition with regard to time between the end of the training and the first event of drunkenness within 1 year after treatment (primary outcome). More precisely, the time span between treatment and first drunkenness event should be longer for the intervention group when compared to the control group. (2) Participants from the intervention group show stronger decrease in ATOD consumption (secondary outcome). (3) The effectiveness of the intervention is associated with changes in the neurobiological parameters of self-regulation, changes in mindfulness, psychopathological symptoms (strengths and weaknesses), and changes in perceived stress and health-related quality of life. Other parameters like reward anticipation, decision making, and impulse control will be examined on an exploratory basis (for details see Statistical analysis section below).

\section{Methods/design}

\section{Study setting}

The study takes place in the city of Rostock, a city of 200.000 inhabitants in the German federal state of Mecklenburg-Western Pomerania. Boys from special schools for children with learning disabilities and/or with mild to borderline intellectual disabilities will be invited to participate in the study. Moreover, boys meeting the inclusion criteria will be recruited from out- and inpatient psychiatric units and other relevant institutions. A continuing list of cooperating centres for recruitment will be established with the registry.

\section{Trial design}

The study evaluates the effectiveness of a mindfulnessbased intervention in preventing ATOD use in 11-17 years old boys with MBID with special focus on the consumption of alcohol. All adolescents fulfilling inclusion criteria will be randomised to either the intervention group or the active control condition (see Fig. 1). Persons who do not have experiences with alcohol will be invited to be part of a registry. With the registry data, 


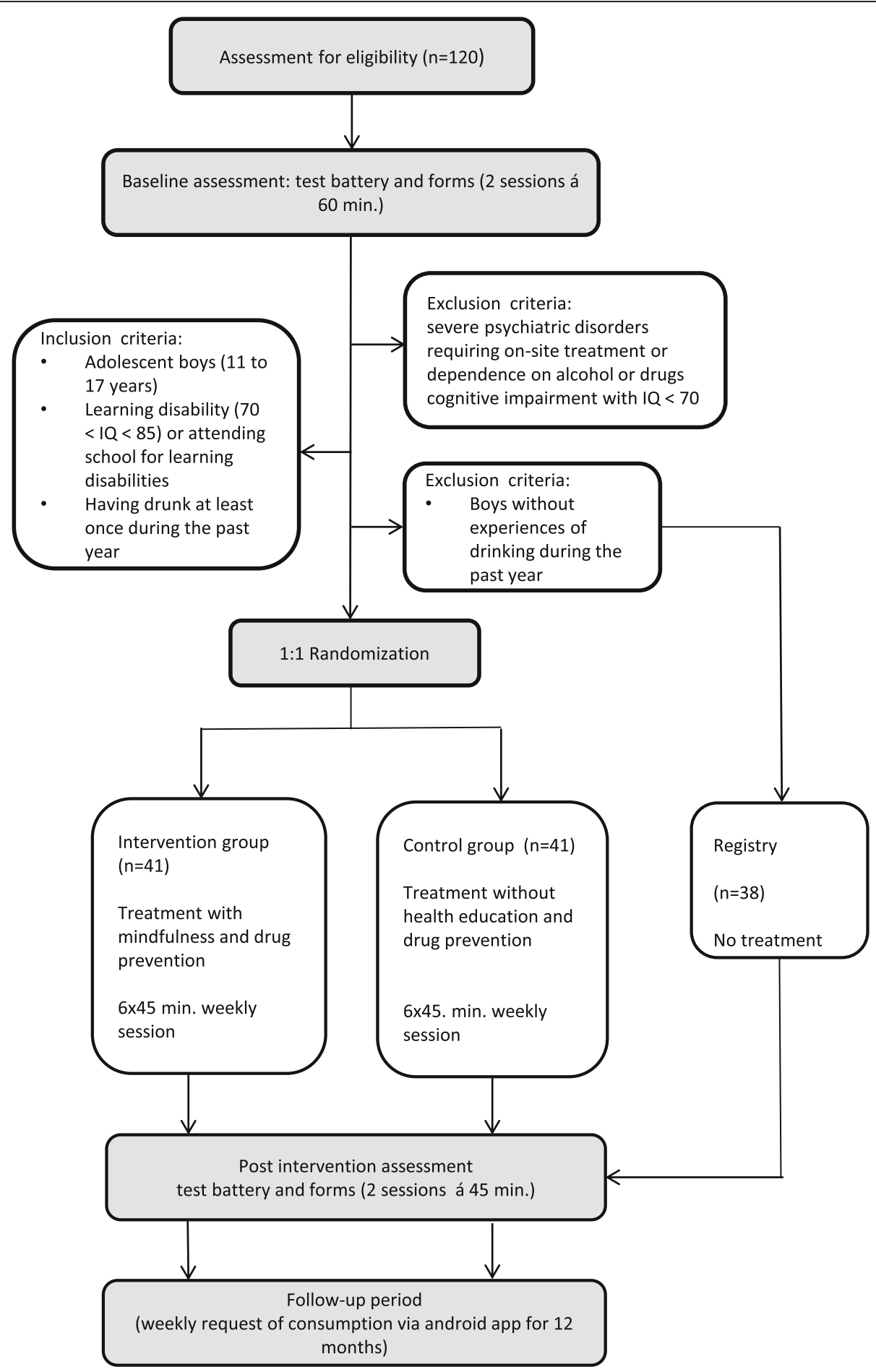

Fig. 1 Study flow diagram

we describe probabilities of starting to consume alcohol depending on personal risk factors. The study is designed as a prospective, randomised, controlled superiority trial proving our concept with two parallel groups. This randomised controlled trial (RCT) will be combined with a small add-on registry study. The first study arm comprises a mindfulness-oriented intervention, the second a sham intervention equal in length and dose, but different in content. Participants from both groups join a 6-week program conducted in one-to-one sessions. The intervention group receives a training containing mindfulness exercises and elements of drug 
prevention. The control group receives a training that contains exercises in health education instead of mindfulness. Participants in the registry receive no intervention and are measured at the same intervals and using the same measurement methods. The trial involves two assessment points (pre- and post-intervention) and a 12 months follow-up period with weekly measurements via the android app movisensXS starting at the last intervention session. Figure 1 shows the flow diagram of the current trial design.

\section{Procedure}

The study timeline is shown in Table 1 . Boys who have consumed any alcohol within the last 12 months before initial assessment and who and their parents/caregivers have given written informed consent will be included in the study $\left(t_{0}\right.$ timing of enrolment). They undergo the baseline measures about the length of two sessions $\left(t_{1}\right.$ and $t_{2}$ ). In case they do not fulfill the inclusion criteria of alcohol use they will be invited to be part of the nonintervention registry. In case they fulfill all inclusion criteria participants will be randomised to either the intervention group or control group in a 1:1 allocation ratio. A central randomisation list will be created with variable block lengths stratified by the recruitment locations school vs. clinics, outpatient clinics and practices. Enrolled participants will be randomized on the base of computer-generated random numbers provided by a research associate of the Institute of Medical Biometry and Epidemiology (IMBE) of the University Medical Center Hamburg-Eppendorf. This assistant is not involved in the practical implementation of the research project. After randomisation, participants get the training over six sessions. After completion of the treatment, participants take part in the post-measurements $\left(t_{3}-t_{4}\right)$. During the post-measurement, the app (movisensXS) is installed on the smartphone of the participants. In case of compatibility problems, a smartphone is handed out to the test persons by the study staff. This smartphone will be only usable for the follow-up survey. For 12 months after intervention, every Sunday afternoon, participants get an app-based reminder and are asked to join the short follow-up survey. Here, they retrospectively report on their substance consumption for the last week directly on their smartphones $\left(t_{5}-t_{57}\right)$ by answering questions via the app.

A voucher worth $5 €$ from a sales brand of a leading consumer electronics retailer can be earned for each training or measurement session.

\section{Intervention}

Mindfulness-oriented substance use prevention program

The intervention results from an extensive research of the literature, a focus-group with teachers from a school for children with learning disabilities, and a feasibility study on $n=32$ participants. In an individual face-toface setting the participants will receive six 45 min sessions once a week. The training is conducted by a person experienced in applications of mindfulness.

The mindfulness practice contains classic elements of Mindfulness Based Stress Reduction (MBSR) and mindfulness exercises adapted for children and youth. The six lessons involve an introduction to mindfulness and exercises on various themes: Awareness of the present moment, body awareness, observation of thoughts and cognition, stress management, perceiving and dealing with positive and negative emotions, and issues that may have an influence on substance use, such as trigger cues and interacting with peers. As basic sources we used "Using the Wisdom of Your Body and Mind to Face Stress, Pain, and Illness: How to Cope with Stress, Pain and Illness" by Kabat-Zinn [25, 34], "Mindfulness-Based Substance Abuse Treatment For Adolescents" by Himmelstein \& Saul [35], "Mindfulness Curriculum for Adolescents by Mindful Schools" [36], "Sitting Still Like a Frog: Mindfulness Exercises for Kids" by Snel [37] and "Learning to Breathe" by Broderick [38].

Sessions of the intervention also include elements of drug education. This subject will be addressed with interactive exercises to meet the requirements of young people with MBID. These tasks are about different addictions, the ability to recognise problematic behaviour, and reflections on stress and resilience factors.

All exercises were tested during an 18-month feasibility period for practicability, comprehensibility and simplicity of tasks to perform, as well as for cognitive load, simple language and length. All sessions, however, are planned for providing sufficient space for explanation and repetition. As the training was extensively piloted, no other modifications during the proof of concept phase are planned.

Since sessions need to fit into school schedules, sessions were adapted to the time frame of a school lesson. In school, sessions are held between or after school hours in a room provided by the school. In the case of outpatient treatment, the sessions take place at the participants' homes, on the premises of the study centre, or in rooms provided by cooperating institutions.

All participants are performing small home works after each training session for the time between the weekly sessions. These are fun tasks to remind them of mindfulness and invite them to try it out in practice and integrate techniques and knowledge into their everyday lives.

\section{Control condition: health education}

There is evidence that mindfulness is a promising treatment approach for people with intellectual disabilities, 
Table 1 Participant timeline of enrolment, treatment and measurement

\begin{tabular}{|c|c|c|c|c|c|c|c|c|}
\hline \multirow[b]{2}{*}{ Timepoint } & \multirow{2}{*}{$\begin{array}{l}\text { Enrolment } \\
t_{0}\end{array}$} & \multicolumn{2}{|c|}{\begin{tabular}{|c|c} 
Baseline \\
assessment
\end{tabular}} & \multirow[t]{2}{*}{ Allocation } & \multicolumn{2}{|c|}{\begin{tabular}{|c|c|} 
Post \\
allocation
\end{tabular}} & \multirow{2}{*}{\begin{tabular}{|l|} 
Weekly \\
Follow- \\
Up \\
t.57 \\
\end{tabular}} & \\
\hline & & $t_{1}$ & $t_{2}$ & & $t_{3}$ & $t_{4}$ & & \\
\hline \multicolumn{8}{|l|}{ Enrolment } & \\
\hline Enrolment & $x$ & & & & & & & \\
\hline Infromed Consent & $x$ & & & & & & & \\
\hline Eligibility Screen & & $x$ & & & & & & \\
\hline Registry population (abstainers) & & $x$ & $x$ & & $\mathrm{x}$ & x & $x$ & \\
\hline \multicolumn{8}{|l|}{ Interventions } & \\
\hline Mindfulnes Intervention & & & & $\bullet$ & 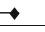 & & & \\
\hline Control Health Intervention & & & & 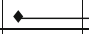 & $\rightarrow$ & & & \\
\hline \multicolumn{8}{|l|}{ Assessments } & \\
\hline Measurement Variable & Measure & & & & & & & \\
\hline \multicolumn{8}{|l|}{ Parents } & \\
\hline Sociodemographics & $\begin{array}{l}\begin{array}{l}\text { Questionnaire of } \\
\text { Statistiches } \\
\text { Bundesamt }\end{array} \\
\end{array}$ & $\mathrm{x}$ & & & & & & \\
\hline Substance use & $\begin{array}{l}\text { self-constructed } \\
\text { measures and first } \\
\text { Item of Alcohol Use } \\
\text { Disorders } \\
\text { Identification Test } \\
\text { (AUDIT) }\end{array}$ & $x$ & & & & & & \\
\hline Experience with mindfulness practice & $\begin{array}{l}\text { self-constructed } \\
\text { measures }\end{array}$ & x & & & & & & \\
\hline $\begin{array}{l}\text { Health-related Quality of Life for Children and Young } \\
\text { People }\end{array}$ & $\begin{array}{l}\text { KIDSCREEN-10 } \\
\text { Index (Parent } \\
\text { Version) }\end{array}$ & $x$ & & & & & & \\
\hline Psychological attributes & $\begin{array}{l}\text { Strengnths and } \\
\text { Difficulties } \\
\text { Questionnaire } \\
\text { (SDQR-D, Parent } \\
\text { version) }\end{array}$ & $x$ & & & & & & \\
\hline Corona-related stress perception & $\begin{array}{l}\text { Adadption of } \\
\text { CoRonalrus } \\
\text { Heanth Irpact } \\
\text { Survey (CRISIS) } \\
\text { vo.1. }\end{array}$ & $x$ & & & & & & \\
\hline \multicolumn{8}{|l|}{ child } & \\
\hline Intelligence & \begin{tabular}{|l|} 
Wechsler \\
Nonverbal Scale of \\
Abitity (brief \\
version)
\end{tabular} & & $\mathrm{x}$ & & & & & \\
\hline Parental substance use & $\begin{array}{l}\text { self-constructed } \\
\text { measures }\end{array}$ & & $x$ & & & & & \\
\hline Sociodemographics & $\begin{array}{l}\begin{array}{l}\text { Questionnaire of } \\
\text { Statititsches } \\
\text { Bundesamt }\end{array} \\
\end{array}$ & $\mathrm{x}$ & & & & & & \\
\hline $\begin{array}{l}\text { Health-related Quality of Life for Children and Young } \\
\text { People }\end{array}$ & $\begin{array}{l}\text { KIISCREEEN-10 } \\
\text { Index }\end{array}$ & $\times$ & & & $x$ & & & \\
\hline Mindfulness & $\begin{array}{l}\text { Mindful Attention } \\
\text { and Awareness } \\
\text { Scale for } \\
\text { Addecsents } \\
\text { (MAAS-A) }\end{array}$ & $\mathrm{x}$ & & & $\mathrm{x}$ & & & \\
\hline Experience with mindfulness practice & $\begin{array}{l}\begin{array}{l}\text { self-constructed } \\
\text { measures }\end{array} \\
\end{array}$ & $x$ & & & & & & \\
\hline Emotion regulation & $\begin{array}{l}\text { Difficitities in } \\
\text { Emotion } \\
\text { Regulation Scale } \\
\text { (DERS, 3 Subscales) }\end{array}$ & & $x$ & & & $\mathrm{x}$ & & \\
\hline Psychological attributes & $\begin{array}{l}\text { Strengths and } \\
\text { Difficutlies } \\
\text { Questionnaire } \\
\text { (SDQ-D) }\end{array}$ & $\mathrm{x}$ & & & & $x$ & & \\
\hline Perceived stress & $\begin{array}{l}\text { Perceived Stress } \\
\text { Scale (PSS-4) }\end{array}$ & $x$ & & & $x$ & & & \\
\hline Substance use & $\begin{array}{l}\text { Timeline } \\
\text { Followback (TLFB) }\end{array}$ & $\mathrm{x}$ & & & $\times$ & & & \\
\hline $\begin{array}{l}\text { Personality risk factors for substance misuse (IImpulsivity, } \\
\text { Sensation Seeking, Anxiety Sensitivity, Hopelessness) }\end{array}$ & $\begin{array}{l}\text { Substance Use Risk } \\
\text { Profile Scale } \\
\text { (sURPS) }\end{array}$ & $\mathrm{x}$ & & & $\mathrm{x}$ & & & \\
\hline Peer network & $\begin{array}{l}\begin{array}{l}\text { self-constructed } \\
\text { sociogram }\end{array} \\
\end{array}$ & & $\mathrm{x}$ & & & $\mathrm{x}$ & $x$ & \\
\hline $\begin{array}{l}\text { Neurobehavioral self-regulation (impulse control, reward } \\
\text { anticipation, decision making) }\end{array}$ & $\begin{array}{l}\text { Neuropsychological } \\
\text { testing (Stop-signal } \\
\text { Task, Monetary } \\
\text { Incentive Delay } \\
\text { Task, Gambling } \\
\text { Task) }\end{array}$ & $\mathrm{x}$ & $\mathrm{x}$ & & $\mathrm{x}$ & $x$ & & \\
\hline Prenatal androgen exposure & $\begin{array}{l}\text { Handscan 2D:4D } \\
\text { (photo scanner) }\end{array}$ & & $\mathrm{x}$ & & & & & \\
\hline Corona-related stress perception & $\begin{array}{l}\text { Adaption of } \\
\text { CoRonavirus } \\
\text { Heauth Impact } \\
\text { Survey (CRISIS) } \\
\text { Vo.1. }\end{array}$ & & $\mathrm{x}$ & & & & & \\
\hline Substance use 12 months follow-up & $\begin{array}{l}\text { self-constructed } \\
\text { measures } \\
\text { requested via app } \\
\end{array}$ & & & & & & x & \\
\hline
\end{tabular}


e.g. in the reduction of aggression [39-41]. However, in a review by Chapman et al. [42] on the effectiveness of mindfulness-based interventions in people with intellectual disabilities, these investigations were criticised for being subject to methodological shortcomings. For example, not the treatment but the attachment to or the interpersonal skills of the trainer would be the reason for pre-post changes [42]. In order to control the effect of social bonding, the control group takes place under an active condition. Participants receive an intervention that equals the non-control intervention in terms of setting (face-to-face), dose and duration but, deals with "hot" health issues. Participants will explore three major themes of healthy food, sports and sexuality, with each topic extending over two sessions. As in the mindfulness-condition, content is delivered via interactive tasks, small games, assignment tasks and movement exercises. Both treatments are structured and manualised to the same degree [43] and elements of drug education are equal for both groups (see Table 2). As in the mindfulness-condition, after each session participants will receive fun tasks as homework for weekly reminders of the contents.

\section{Inclusion and exclusion criteria}

Boys will be included in the randomised trial if

- they and their parents/cargegivers give informed consent
- they have declared that they have drunk alcohol during the past year

- they are between 11 and 17 years (clinical/institution recruitment) or between 13 and 17 years (school recruitment)

- they are diagnosed with having a MBID (70<I.Q. < 85 ) or if they are educated in a school for learning disability

The decision about fulfilling the inclusion criteria, and therefore randomisation, can be made only after informed consent was given. This is due to the fact, that many boys have problems to admit, that they drank alcohol, when their parents are around. A clear picture on their consumption pattern will be gained only in the more intimate situation of the first measurement $\left(t_{1}\right)$. Interested boys who meet the criteria but who had not drank alcohol in the previous year are directed to the registry (see Fig. 1) and receive neither the intervention nor the control intervention. Based on estimations from the feasibility study, we plan an oversampling of at least $n=38$ persons.

Boys will be excluded from randomisation if they have 1) no experiences of drinking in the last year; 2) display severe psychiatric disorders requiring on-site treatment or dependence on alcohol or drugs; 3) have a cognitive impairment with I.Q. $\leq 70$. In case they fulfill the second or third criteria, boys will be excluded completely from the study. Boys only fulfilling the first criterion will be

Table 2 Training manuals for intervention group and control group

\begin{tabular}{|c|c|c|}
\hline Session & Intervention group: Mindfulness Intervention & Control group: Health Intervention \\
\hline $\begin{array}{l}\text { Session } \\
1\end{array}$ & $\begin{array}{l}\text { Welcome and overview, flashlight for mood (every session), meaning of } \\
\text { mindfulness, attitudes of mindfulness, first meditation practice, introduction } \\
\text { of the breath as an anchor }\end{array}$ & $\begin{array}{l}\text { Welcome and introduction, flashlight for mood, (every } \\
\text { session) } \\
\text { Healthy food: Nutrition pyramid, food ingredients; Nutri-Score } \\
\text { rating system and reflection of the own eating behaviour }\end{array}$ \\
\hline $\begin{array}{l}\text { Session } \\
2\end{array}$ & $\begin{array}{l}\text { Meditation practice, mindful coping with desire, mindful eating a raisin vs. } \\
\text { piece of chocolate }\end{array}$ & $\begin{array}{l}\text { Healthy food: Hidden sugar in your food, game with sugar } \\
\text { cubes, taking pictures } \\
\text { of packaged food with the amount of sugar }\end{array}$ \\
\hline $\begin{array}{l}\text { Session } \\
3\end{array}$ & $\begin{array}{l}\text { Be mindful, sense your body, introduction to and practice of the body scan } \\
+ \\
\text { Desire, craving and consumption, } \\
\text { self-rating of consumption }\end{array}$ & $\begin{array}{l}\text { Meaning of sports and physical health in everyday life, } \\
\text { current body posture, ergonomic sitting tools } \\
+ \\
\text { Desire, craving and consumption, } \\
\text { self-rating of consumption }\end{array}$ \\
\hline $\begin{array}{l}\text { Session } \\
4\end{array}$ & $\begin{array}{l}\text { Meditation practice, moods and current emotions, drawing moods as a } \\
\text { weather report } \\
+ \\
\text { Memory Game: Addiction and addictive behaviour }\end{array}$ & $\begin{array}{l}\text { Development, long term effects and consequences of bad } \\
\text { motion habits, sport exercises for a healthy and strong back } \\
+ \\
\text { Memory Game: Addiction and addictive behaviour }\end{array}$ \\
\hline $\begin{array}{l}\text { Session } \\
5\end{array}$ & $\begin{array}{l}\text { Mindfulness of emotion: Identify positive, negative and neutral emotions, } \\
\text { stop the autopilot, sense emotions } \\
+ \\
\text { Card game: "Enjoying life" }\end{array}$ & $\begin{array}{l}\text { Sex education: Reconsideration of gender stereotypes; } \\
\text { sexuality in the context of pleasure, love and responsibility } \\
+ \\
\text { Card game: "Enjoying life" }\end{array}$ \\
\hline $\begin{array}{l}\text { Session } \\
6\end{array}$ & $\begin{array}{l}\text { Mindfulness of thoughts: The power of thoughts, observe and produce } \\
\text { thoughts, mindful walking } \\
+ \\
\text { Card game: Stress in different situations, Evaluation and personalised stress } \\
\text { management }\end{array}$ & $\begin{array}{l}\text { Sex education: sexual harassment in online networks and } \\
\text { chats, strategies for action to say no } \\
+ \\
\text { Card game: Stress in different situations, Evaluation and } \\
\text { personalised stress management }\end{array}$ \\
\hline
\end{tabular}


directed into the registry and will be observed for a possible initiation of drinking during the study period of 1 year.

\section{Data collection}

\section{Primary outcome}

Events of drunkenness are collected retrospectively after completion of the training on a weekly basis by the movisensXS app for the last 7 days. From these measurements, the time to first event of drunkenness is derived. In case of drunkenness events, quantitative measures of alcohol consumption are taken as numbers of units (bottles, glasses of various beverages) in an easyto-answer manner. A weekly electronic measurement at $5 \mathrm{pm}$ every Sunday proved to be feasible as did the research tool designed by the researchers on a flexible platform (movisensXS, Version 1.5.8, (movisens GmbH, Karlsruhe, Germany)).

\section{Secondary and other outcomes}

Secondary outcomes include self-reported alcohol use during the first year after intervention as a quantitative measure of consumption taken on a weekly basis using a smartphone-based research tool.

For all participants, the number of cigarettes will be inquired weekly.

Furthermore, emotion regulation, neurobehavioural self-regulation, trait mindfulness, psychological attributes, perceived stress and health-related quality of life and will be measured before and after the intervention. In case of drunkenness events, the weekday of the event and event-related social networks will be recorded. The consumption of illicit drugs of any kind will be asked for on a weekly basis. Sociodemographic data on the adolescent's family contain consumption habits in the parental household (specific target variables and measurements are listed in Table 1).

\section{Plans for data collection Follow up}

Substance use Our sampling method via movisensXS involves asking participants weekly about drunkenness events and the consumption of alcohol, tobacco and illicit drugs. For binging events, they will be asked for the timing, quantity and experience. The questioning takes a maximum of $3 \mathrm{~min}$. It starts the first week after the intervention and should be carried out weekly for a total of 52 weeks.

\section{Pre/ post measurements}

Most of the measures taken are harmonised throughout the projects of the IMAC-consortium [44-47].
Sociodemographics Items are based on the questionnaire of the Statistisches Bundesamt for recording sociostructural survey characteristics in the population [48].

Substance use The Timeline Followback (TLFB) is a calendar method in which participants are asked retrospectively about their consumption of alcohol, nicotine, cannabis and other drugs, establishing a 30-days-before baseline and a post-measurement calendar [49].

Family risk factors In order to record risky alcohol consumption, addiction or abuse, the alcohol consumption of parents/caregivers is measured with the help of a German translation of the 10-item Alcohol Use Disorders Identification Test (AUDIT) [50], of which one item will be used. Health-relevant data on smoking, sport, eating and sleeping behaviour in the family will be collected via a self-authored items.

Mindfulness The Mindful Attention Awareness ScaleAdolescents (MAAS-A) for young people between 14 and 18 years of age contains 15 items for the assessment of dispositional mindfulness [51]. The questionnaire takes a maximum of $10 \mathrm{~min}$ with a good internal consistency (alpha $=.82)$ and retest reliability $(\mathrm{r}=.79)$.

Personality Substance Use Risk Profile Scale (SURPS) is a 23-item self-assessment questionnaire that includes four personality risk factors for substance abuse (impulsiveness, sensation-seeking, anxiety sensitivity, and hopelessness) [52].

Intelligence The Wechsler Nonverbal Scale of Ability (WNV) is a non-verbal general cognitive ability assessment for children, teenagers, and young adults aged 4 to 21. The brief version lasts requires $15-20 \mathrm{~min}$ and consists of the two subtests matrices and spatial span [53]. It will be used in cases when no sufficient information about intelligence level or schooling can be found.

Neuropsychological testing This neuropsychological computer-based testing includes three separate test paradigms.

1) Stop-Signal Task for recording response inhibition.

2) Monetary Incentive Delay Task measuring reward anticipation.

3) Cambridge Gambling Task assessing decisionmaking and risk-taking behaviour.

The neuropsychological test battery takes about 40 min and was designed by a subproject of the IMAC consortium [54]. 
Perceived stress The short form of the Perceived Stress Scale (PSS-4) is a four-item well-validated selfassessment of perceived stress during the last month [55].

Emotion regulation The Difficulties in Emotion Regulation Scale (DERS; Gratz \& Roemer, [56], German version Ehring et al., [57]) is a well-validated and reliable selfreport measure of emotion regulation and dysregulation (Cronbachs alpha $=.95$, split-half reliability $=.96$ ) targeting the 11-17 year olds. In the current trial, we are focusing on 3 of the 5 subscales, (1) Difficulties engaging in goal-directed behaviour (goals), (2) Impulse control difficulties (impulse) and (3) Limited access to emotion regulation strategies (strategies).

Health-related quality of life The health-related quality of life of children and adolescents will be assessed with the Kidscreen-10 Index by means of self-disclosure and external assessment by parents in a pre measurment [58]. The 10-item-questionnaire provides a good internal consistency reliability (Cronbach's Alpha $=.82$ ) and a moderate retest reliability $(\mathrm{r}=.73)$.

Influence of peers A small self-developed network inventory asks for peer influences on alcohol and tobacco consumption. Three name-generators of most important friends are explored in greater detail for descriptive and injunctive social contagion, selectivity, and importance.

Psychopathological symptoms The German version of the Strengths and Difficulties Questionnaire (SDQ, [59]; German version by Woerner [60, 61], is suitable for children and adolescents between 3 and 17 years of age. The test comprises 25 positive and negative attributes of the 5 subscales emotional symptoms, conduct problems, hyperactivity/inattention, peer relationship problems and prosocial behaviour. The same 25 items are included in a questionnaire version to be filled in by the parents.

Impact of the Covid-19 situation Corona-related stress perception is measured with a short adaptation of CoRonavIruS Health Impact Survey (CRISIS) V0.1 [62]. The questionnaire consists of 12 items in the parent version and 9 items in the children version.

Prenatal androgen exposure During the intrauterine period, androgen exposure organises the brain with lifelong neurobiological and behavioural effects. There is multi-level evidence that higher prenatal androgen exposure increases the risk for substance use disorders in later life [63-66] and also affects mindfulness [67] and the body mass index [68]. Within the projects of the IMAC-Mind Consortium, the participants' second-to- fourth-finger length ratios (2D:4D), a proxy of prenatal androgen exposure, will be quantified via optical measurement.

\section{Statistical analysis \\ Sample size}

For the primary outcome "time to first event of drunkenness", we calculated the sample size for a logrank test comparing the intervention and control group. In the literature, we did not find data referring to students with MBID for precise estimating of the base rates of survival. Hence, we refer to the European School Survey Project on Alcohol and other Drugs (ESPAD, see Introduction). ESPAD-data indicates that about $60 \%$ of students report at least one event of drunkenness during the last year, which makes an event-free survival rate of 0.4 in the control group. In the absence of evidence-based assumptions on the effectiveness of the intervention, we estimate that the intervention will drop down the events of drunkenness from a base rate of 60 to $28 \%$, which corresponds to an event-free survival rate of 0.72 in the intervention group. This leads to a hazard ratio of 0.36 . With a power of $80 \%$ and a significance level of $5 \%$ (two-sided hypothesis), we need an overall sample size of 82 participants (41 participants per group) to detect this difference. We assume that we lose $30 \%$ of the participants in each group during the study duration. These observations are censored. Furthermore, we expect no one to switch groups. The study is planned without accrual period.

For the most important secondary outcomes "quantity of alcohol units /number of tobacco cigarettes", we can show median effects of .65 in terms of Cohens $d$ with this sample size and with a type I error of $\alpha=.05$ (twosided hypothesis), a power of $1-\beta=.80$ and a correlation between baseline and follow-up of $r=.50$. The sample size calculation was conducted with PASS 15 based on the modules "Logrank Tests" and "Analysis of Covariance".

\section{Statistical methods for primary and secondary outcomes}

The descriptive statistics will be presented separately for every group and for the total sample. The primary and secondary analysis will be based on the intention-totreat population, which includes all participants randomised. For the primary outcome "time to first event of drunkenness", a logrank test will be calculated to compare group differences in survival curves. The resulting statistical test for group comparison will be performed two-sided at the 5\% significance level. The analysis will be repeated in the per-protocol population. In an additional analysis, we will extend this time-to-event-analysis to a Cox regression to adjust our results for the following covariates: intelligence, age, mindfulness, 
mental health, and family risks. If the event "drunkenness" occurs frequently enough in the individual participant, for the secondary analysis we will use an appropriate extension of the Cox model to deal with recurrent events and a Poisson regression using the count of the events as the dependent variable. For the most important secondary outcomes, change from baseline of the number of alcohol units and change from baseline of the number of cigarettes, a baseline-adjusted linear mixed model will be calculated for each outcome with participants as a random effect and group (intervention vs. control), time and recruitment location (schools vs. clinics, outpatient clinics, and practices) as fixed effects, and the respective baseline value as a covariate. The time by group interaction will be tested, and if the interaction is not significant, the interaction will not be included in the model. In this model, missing values will be directly imputed to enable an intention-to-treat analysis, which results in unbiased estimators under the missing-atrandom-assumption. For further secondary outcomes (neuropsychological testing and questionnaires), a baseline adjusted analysis of covariance will be determined with the respective change from baseline to postintervention as a dependent variable, group and recruitment location as independent variables, and the respective baseline value as a covariate. The analysis of all secondary outcomes will be performed in an exploratory manner. Interim analyses are not planned. Exploratory analyses will be performed for possible intervening factors, such as neurobehavioural parameters, mindfulness (trait) or quality of life. The analysis of the registry study will be performed in an exploratory manner. Probabilities of starting to consume alcohol will be described descriptively.

Standard statistical software as STATA (Version 16.0 or newer), R (Version 4.0.3 or newer), SAS (Version 9.4 or newer) or SPSS (Version 25 or newer) will be used for the statistical analyses.

\section{Discussion}

Although there are several mindfulness programs for children and adolescents, we found no programs aimed at adolescents with MBID. With this study, we want to test a new program tailored to this group. A previously conducted feasibility study showed that mindfulness can be successfully applied and implemented in children and adolescents with MBID. In a randomised controlled study, we want to test the effectiveness of the newly developed program against an active control condition to prove this concept.

The prevention program combines elements based on currently published and partly evaluated mindfulness programs and courses designated for the use in children and adolescents, based on the work of Jon Kabat-Zinn.
Since we cannot exclude the possibility that an intensive engagement with the young people alone will foster all sorts of improvements in mindfulness and health behaviour, we have chosen an active control condition, which is carried out in a similar face-to-face way and is identi$\mathrm{cal}$ in terms of dose and length to the intervention. Both the intervention and the control program are combined with elements of classical drug education which were adapted in comprehensibility and difficulty to youth with MBID. For the implementation of the program, we have consciously decided on a face-to-face setting as it was used for people with reduced cognitive abilities [69]. That way, we are able to better meet the individual needs of the boys with MBID, but also to exclude other interfering social factors, such as social pressures to play "cool". With our study, we want to evaluate whether mindfulness can help substantially to reduce alcohol consumption among young boys with MBID. Based on the secondary outcomes, we plan to assess whether mindfulness has further effects on neurobehavioural regulation, experiences and the everyday life of the adolescents. If the concept proves to be effective, we would published the results in peer-reviewed journals and mindfulness could be seen as a new promising approach in prevention work with young people with MBID.

\section{Trial status}

Protocol version number $\mathrm{v} 1.0,31.07 .2020$. The study has now begun and recruitments starts in November 2020.

\section{Abbreviations}

ATOD: Alcohol, tobacco and other drugs; AUD: Alcohol use disorder; AUDIT: Alcohol Use Disorders Identification Test; CRISIS: Coronavirus Health Impact Survey; DERS: Difficulties in Emotion Regulation Scale; DLR: Deutsches Zentrum für Luft- und Raumfahrt e. V [German Aerospace Center]; ESPA D: European School Survey Project on Alcohol and Other Drugs; HBSC: Health Behaviour of School Children; IMAC-Mind: Improving Mental Health and Reducing Addiction in Childhood and Adolescence through Mindfulness; IMBE: Institute of Medical Biometry and Epidemiology; MBID: Mild to borderline intellectual disabilities; MBSR: Mindfulness-based stress reduction; MASS-A: Mindful Attention Awareness Scale for Adolescents; MTF: Monitoring the Future study; NSDUH: National Survey on Drug Use and Health; PSS: Perceived Stress Scale; RCT: Randomised controlled trial;

SDQ: Strengths and Difficulties Questionnaire; SUD: Substance use disorder; SURPS: Substance Use Risk Profile Scale; WNV: Wechsler Nonverbal Scale of Ability (WNV)

\section{Acknowledgements}

With the public funded research project IMAC-Mind: Improving Mental Health and Reducing Addiction in Childhood and Adolescence through Mindfulness: Mechanisms, Prevention and Treatment (2017-2021, 01GL1745E), the Federal Ministry of Education and Research contributes to improving the prevention and treatment of children and adolescents with substance use disorders and associated mental disorders. The Project coordination is realised by the German Center of Addiction Research in Childhood and Adolescence at the University Medical Center Hamburg-Eppendorf. The consortium comprises seven projects in Germany. Principle Investigators are: Rainer Thomasius (Coordinator, University Medical Center Hamburg-Eppendorf), Tobias Banaschewski und Herta Flor (both Central Institute for Mental Health, Mannheim), Johannes Kornhuber (Friedrich-Alexander-Universität Erlangen-Nürnberg), Michael Klein (Catholic University of Applied Sciences, Cologne), Olaf Reis (University Medicine of Rostock), 
Tanja Legenbauer (Ruhr-University Bochum), Antonia Zapf (University Medical Center Hamburg-Eppendorf). Further members of the consortium are: Nicolas Arnaud, Austermann Maria, Christiane Baldus, Anne Daubmann, Léa Josette Laurenz, Sabrina Kunze, Sophie Luise Schiller, Michael Supplieth (University Medical Center Hamburg-Eppendorf), Frauke Nees, Karl Gottfried, Stella Guldner, Sabina Millenet, Maren Prignitz (Central Institute for Mental Health, Mannheim), Bernd Lenz, Peter Fasching, Matthias Beckmann, Hartmut Heinrich, Verena Nadine Buchholz, Anna Eichler, Lothar Häberle, Christiane Mühle, Patrick Stelzl, Bernhard Volz (Friedrich-Alexander-University Erlangen-Nürnberg), Katharina Ise, Diana Moesgen (Catholic University of Applied Sciences, Cologne), Lucie Waedel (University Medicine of Rostock), Martin Holtmann, Regina Herdering, Carina Maria Huhn, Laura Mokros (Ruhr-University Bochum). For more information please visit our homepage www.IMAC-Mind.de.

\section{Name and contact information for the trial sponsor}

Department of Child and Adolescent Psychiatry and Neurology, University Medical Center Rostock, Gehlsheimer str. 20, 18,147 Rostock.

\section{Authors' contributions}

OR conceived of the study and study design. LW was responsible for the development of the intervention and control intervention. LW will implement the treatment sessions in intervention and control group. AD and AZ conceived the statistical calculations. OR and LW wrote the manuscript which was reviewed and approved by all authors.

\section{Funding}

This project was funded by the Federal Ministry of Education and Research in Germany (Reference number 01GL1745E) as part of the research collaboration under "IMAC-Mind: Improving Mental Health and Reducing Addiction in Childhood and Adolescence through Mindfulness: Mechanisms, Prevention and Treatment". This funding source had no role in the design of the study and collection, analysis, and interpretation of data or writing this manuscript.

The trial sponsor can be contacted at:

Deutsches Zentrum für Luft- und Raumfahrt e. V. (DLR) Projektträger Heinrich-Konen-Str. 153227 Bonn Germany. Open Access funding enabled and organized by Projekt DEAL.

\section{Availability of data and materials}

Not applicable.

\section{Ethics approval and consent to participate}

The current study complies with the standards of Good Clinical Practice (GCP) and was approved by the Ethics Committee of the Medical Faculty of the University of Rostock (registration number: A 2018-0002, amendment after feasibility period of 26.05.2020). According to the ethics commission, there are no objections from a professional and ethical point of view to the implementation and continuation of the research project. Furthermore a Data and Safety Monitoring Board has been established in which persons independent of the study stuff and sponsor ensure the safety of the participants and the data collected. All participants receive detailed written information about the study project and give informed consent to the research team. Informed parental (or from legal guardian) consent will be received for all participants under the age of 16 . Extensive study information (flyer) will be handed out and opportunities to ask questions will be provided. If unexpectedly serious adverse events occur, they will be documented and reported to the Data and Safety Monitoring Board. This board is an independent consultative committee that can make recommendations to the study organisers. Together with the research team, a decision will be made on how to proceed (e.g. discontinuing training, exclusion of participants from the study, counselling or medical support). Furthermore, the study is supervised by the external monitoring company responsible for essential organizational and administrative services for the preparation, execution and follow-up of this clinical study.

\section{Consent for publication}

Not applicable.

\section{Competing interests}

The authors declare that they have no competing interests.

\section{Author details}

'Department of Child and Adolescent Psychiatry and Neurology, University Medical Centre Rostock, Gehlsheimer Str. 20, 18147 Rostock, Germany. ${ }^{2}$ Department of Medical Biometry and Epidemiology, University Medical Centre Hamburg-Eppendorf, Martinistr. 52, 20246 Hamburg, Germany.

Received: 5 November 2020 Accepted: 11 November 2020

Published online: 25 November 2020

\section{References}

1. Substance Abuse and Mental Health Services Administration. National Survey on Drug Use and Health (NSDUH) 2018 (NSDUH-2019) Public-Use File Dataset. Available at: https://www.datafiles.samhsa.gov/study/nationalsurvey-drug-use-and-health-nsduh-2018-nid18757. Accessed 15 Nov 2019.

2. ESPAD Group. ESPAD report 2015: results from the European school survey project on alcohol and other drugs. Luxembourg: Publications Office of the European Union; 2016.

3. Hibell B, Guttormsson U, Ahlström S, Balakireva O, Kokkevi T, Kraus L. The 2011 ESPAD report - substance use among students in 36 European countries; 2012

4. HBSC-Studienverbund Deutschland (Autorlnnen Moor I, Hinrichs R, Heilmann K, Richter M). Studie Health Behaviour in School-aged Children Faktenblatt "Alkoholkonsum von Kindern und Jugendlichen" 2020.

5. HBSC-Studienverbund Deutschland (Autorlnnen Moor I, Hinrichs R, Heilmann K, Richter M). Studie Health Behaviour in School-aged Children Faktenblatt "Tabakkonsum von Kindern und Jugendlichen" 2020.

6. Orth B, Merkel C. Der Alkoholkonsum Jugendlicher und junger Erwachsener in Deutschland. Köln: Ergebnisse des Alkoholsurveys 2018 und Trends; 2019.

7. Lange C, Manz K, Rommel A, Schienkiewitz A, Mensink G. Alkoholkonsum von Erwachsenen in Deutschland: Riskante Trinkmengen, Folgen und Maßnahmen: Robert Koch-Institut, Epidemiologie und Gesundheitsberichterstattung; 2016.

8. Merline AC, O'Malley PM, Schulenberg JE, Bachman JG, Johnston LD. Substance use among adults 35 years of age: prevalence, adulthood predictors, and impact of adolescent substance use. Am J Public Health 2004;94(1):96-102. https://doi.org/10.2105/ajph.94.1.96.

9. Vieira D, Ribeiro de Araújo M, Laranjeira R. Evidence of association between early alcohol use and risk of later problems. Braz J Psychiatry. 2007;29:222-7. https://doi.org/10.1590/s1516-44462007000300006.

10. Laucht M, Schmid B. Früher Einstieg in den Alkohol- und Tabakkonsum Indikator für eine erhöhte Suchtgefährdung? Z Kinder Jugendpsychiatr Psychother. 2007;35(2):137-43. https://doi.org/10.1024/1422-4917.35.2.137.

11. Reis $\mathrm{O}$, Wetzel $\mathrm{B}$, Häßler F. Mild or borderline intellectual disability as a risk for alcohol consumption in adolescents - a matched-pair study. Res Dev Disabil. 2017;63:132-41. https://doi.org/10.1016/j.ridd.2015.11.007.

12. van Duijvenbode N, VanDerNagel JEL. A systematic review of substance use (disorder) in individuals with mild to borderline intellectual disability. Eur Addict Res. 2019;25(6):263-82. https://doi.org/10.1159/000501679.

13. Emerson E, Turnbull L. Self-reported smoking and alcohol use among adolescents with intellectual disabilities. J Intellect Disabil. 2005;9(1):58-69. https://doi.org/10.1177/1744629505049730.

14. Pacoricona Alfaro DL, Ehlinger V, Spilka S, Ross J, Sentenac M, Godeau E. Alcohol, tobacco and cannabis use: do students with mild-intellectual disability mimic students in the general population? Res Dev Disabil. 2017; 63:118-31. https://doi.org/10.1016/j.ridd.2016.10.009.

15. Emerson E, Robertson J, Baines S, Hatton C. Predictors of self-reported alcohol use and attitudes toward alcohol among 11-year-old British children with and without intellectual disability. J Intellect Disabil Res. 2016;60(12): 1212-26. https://doi.org/10.1111/jir.12334.

16. Substance Abuse and Mental Health Services Administration. Key substance use and mental health indicators in the United States: results from the 2018 National Survey on drug use and health. Center for Behavioral Health Statistics and Quality, Substance Abuse and Mental Health Services Administration: Rockville; 2019.

17. Kiewik M, VanDerNagel JEL, Kemna LEM, Engels RCME, DeJong CAJ. Substance use prevention program for adolescents with intellectual disabilities on special education schools: a cluster randomised control trial. J Intellect Disabil Res. 2016;60(3):191-200. https://doi.org/10.1111/jir.12235.

18. Robertson J, Emerson E, Baines S, Hatton C. Self-reported smoking, alcohol and drug use among adolescents and young adults with and without mild 
to moderate intellectual disability. J Intellect Develop Disabil. 2020;45(1):3545. https://doi.org/10.3109/13668250.2018.1440773.

19. Rimmer $J H$, Braddock D, Marks B. Health characteristics and behaviors of adults with mental retardation residing in three living arrangements. Res Dev Disabil. 1995;16(6):489-99. https://doi.org/10.1016/08914222(95)00033-x.

20. Didden R, Embregts P, van der Toorn M, Laarhoven N. Substance abuse, coping strategies, adaptive skills and behavioral and emotional problems in clients with mild to borderline intellectual disability admitted to a treatment facility: a pilot study. Res Dev Disabil. 2009;30(5):927-32. https://doi.org/10. 1016/j.ridd.2009.01.002

21. Schmidt S. Was ist Achtsamkeit? Herkunft, Praxis und Konzeption. SUCHT Zeitschrift für Wissenschaft und Praxis / J Addict Res Pract. 2014;60:13-9. https://doi.org/10.1024/0939-5911.a000287.

22. Johnson RLL. A brief history of mindfulness in addictions treatment. Int Adv Couns. 2019;41(2):284-95. https://doi.org/10.1007/s10447-019-09372-y.

23. Brown KW, Creswell JD, Ryan RM. Handbook of mindfulness: theory, research,practice. New York: The Guilford Press; 2015.

24. Shapiro S, Weisbaum E. History of mindfulness and psychology. In Thompson WR, editor. Oxford research encyclopedias. Oxford University Press; 2020. https://doi.org/10.1093/acrefore/9780190236557.013.678.

25. Kabat-Zinn J. Full Catastrophe Living: Using the Wisdom of Your Body and Mind to Face Stress, Pain, and IIIness. Using the Wisdom of Your Body and Mind to Face Stress, Pain, and IIIness. Delta; 1990.

26. Bodhi B. What does mindfulness really mean? A Canonical Perspective Contemporary Buddhism. 2011;12:19-39. https://doi.org/10.1080/14639947. 2011.564813.

27. Bishop SR, Lau M, Shapiro S, Carlson L, Anderson ND, Carmody J, et al. Mindfulness: a proposed operational definition. Clin Psychol Sci Pract. 2004; 11(3):230-41. https://doi.org/10.1093/clipsy.bph077.

28. Mahmood L, Hopthrow T, Randsley de Moura G. A Moment of Mindfulness: Computer-Mediated Mindfulness Practice Increases State Mindfulness. PLoS One. 2016;11:e0153923. https://doi.org/10.1371/journal.pone.0153923.

29. Chiesa A, Serretti A. Are mindfulness-based interventions effective for substance use disorders? A systematic review of the evidence. Subst Use Misuse. 2014;49(5):492-512. https://doi.org/10.3109/10826084.2013.770027.

30. Hochster A, Block-Lerner J, Marks DR, Erblich J. Mindfulness buffers the effects of cue-induced craving on alcohol demand in college drinkers. Addict Behav. 2018;84:53-6. https://doi.org/10.1016/j.addbeh.2018.03.013.

31. Karyadi KA, VanderVeen JD, Cyders MA. A meta-analysis of the relationship between trait mindfulness and substance use behaviors. Drug Alcohol Depend. 2014;143:1-10. https://doi.org/10.1016/j.drugalcdep.2014.07.014

32. Dunning DL, Griffiths K, Kuyken W, Crane C, Foulkes L, Parker J, et al. Research review: the effects of mindfulness-based interventions on cognition and mental health in children and adolescents - a meta-analysis of randomized controlled trials. J Child Psychol Psychiatry Allied Discip. 2019;60(3):244-58. https://doi.org/10.1111/jcpp.12980.

33. Tobler N, Roona M, Ochshorn P, Marshall D, Streke A, Stackpole K. Schoolbased adolescent drug prevention programs: 1998 meta-analysis. J Prim Prev. 2000;20:275-336. https://doi.org/10.1023/a:1021314704811.

34. Kabat-Zinn J. Gesund durch Meditation. Barth: O. W; 2013.

35. Himelstein S, Saul S. Mindfulness-based substance abuse treatment for adolescents. Routledge; 2016. p. 234.

36. Schools M. Mindfulness curriculum for adolescents; 2015.

37. Snel E. Stillsitzen wie ein Frosch: Goldmann Verlag; 2013.

38. Broderick PC. Learning to breathe: a mindfulness curriculum for adolescents to cultivate emotion regulation, attention, and performance. New Harbinger; 2013.

39. Hwang YS, Kearney P. A systematic review of mindfulness intervention for individuals with developmental disabilities: long-term practice and long lasting effects. Res Dev Disabil. 2013;34(1):314-26. https://doi.org/10.1016/j. ridd.2012.08.008.

40. Singh NN, Wahler RG, Adkins AD, Myers RE. Soles of the feet: a mindfulnessbased self-control intervention for aggression by an individual with mild mental retardation and mental illness. Res Dev Disabil. 2003;24(3):158-69. https://doi.org/10.1016/s0891-4222(03)00026-x.

41. Singh NN, Lancioni GE, Winton AS, Curtis WJ, Wahler RG, Sabaawi M, et al. Mindful staff increase learning and reduce aggression in adults with developmental disabilities. Res Dev Disabil. 2006;27(5):545-58. https://doi. org/10.1016/j.ridd.2005.07.002.
42. Chapman M, Hare D, Caton S, Donalds D, Mclnnis E, Mitchell D. The use of mindfulness with people with intellectual disabilities: a systematic review and narrative analysis. Mindfulness. 2013;4. https://doi.org/10.1007/s12671013-0197-7.

43. Crits-Christoph P, Baranackie K, Kurcias J, Beck A, Carroll K, Perry K, et al. Meta-analysis of therapist effects in psychotherapy outcome studies. Psychother Res. 1991;1(2):81-91. https://doi.org/10.1080/ 10503309112331335511.

44. Moesgen D, Ise K, Dyba J, Klein M. Evaluation of the mindfulnessaugmented "Trampoline" programme - a German prevention programme for children from substance-involved families tested in a cluster-randomised trial. BMC Public Health. 2019;19(1):571. https://doi.org/10.1186/s12889-0196875-1.

45. Lenz B, Eichler A, Schwenke E, Buchholz VN, Hartwig C, Moll GH, et al. Mindfulness-based stress reduction in pregnancy: an app-based Programme to improve the health of mothers and children (MINDFUL/PMI study). Geburtshilfe Frauenheilkd. 2018;78(12):1283-91. https://doi.org/10.1055/a0677-2630.

46. Baldus C, Mokros L, Daubmann A, Arnaud N, Holtmann M, Thomasius R, et al. Treatment effectiveness of a mindfulness-based inpatient group psychotherapy in adolescent substance use disorder - study protocol for a randomized controlled trial. Trials. 2018;19(1):706. https://doi.org/10.1186/ s13063-018-3048-y.

47. Arnaud N, Baldus C, Laurenz LJ, Bröning S, Brandt M, Kunze S, et al. Does a mindfulness-augmented version of the German strengthening families program reduce substance use in adolescents? Study protocol for a randomized controlled trial. Trials. 2020;21(1):114. https://doi.org/10.1186/ s13063-020-4065-1.

48. Statistisches Bundesamt: https://www.destatis.de/DE/Methoden/ Demografische-Regionale-Standards/textbaustein-demografische-standards. html. Accessed 06.04.2020.

49. Sobell MB, Sobell LC. Stepped care as a heuristic approach to the treatment of alcohol problems. J Consult Clin Psychol. 2000;68(4):573-9.

50. World HO. AUDIT: the alcohol use disorders identification test: guidelines for use in primary health care / Thomas F. Babor [et al.] 2nd ed. Geneva: World Health Organization; 2001.

51. Brown KW, West AM, Loverich TM, Biegel GM. Assessing adolescent mindfulness: validation of an adapted mindful attention awareness scale in adolescent normative and psychiatric populations. Psychol Assess. 2011;23(4):1023-33. https://doi.org/10.1037/a0021338.

52. Woicik PA, Stewart SH, Pihl RO, Conrod PJ. The substance use risk profile scale: a scale measuring traits linked to reinforcement-specific substance use profiles. Addict Behav. 2009;34(12):1042-55. https://doi.org/10.1016/j. addbeh.2009.07.001

53. Wechsler D, Naglieri JA. Wechsler nonverbal scale of ability (WNV). Harcourt Assessment: San Antonio; 2006

54. Nees F, Tzschoppe J, Patrick CJ, Vollstädt-Klein S, Steiner S, Poustka L, et al. Determinants of early alcohol use in healthy adolescents: the differential contribution of neuroimaging and psychological factors. Neuropsychopharmacology. 2012;37(4):986-95. https://doi.org/10.1038/npp. 2011.282.

55. Cohen S, Kamarck T, Mermelstein R. Perceived stress scale. Measuring stress: A guide for health social scientists. German translation: Engling; 2010.

56. Gratz KL, Roemer L. Multidimensional assessment of emotion regulation and Dysregulation: development, factor structure, and initial validation of the difficulties in emotion regulation scale. J Psychopathol Behav Assess. 2004; 26(1):41-54. https://doi.org/10.1023/b:joba.0000007455.08539.94.

57. Ehring T, Svaldi J, Tuschen-Caffier B, Berking M. Validierung der Difficulties in Emotion Regulation Scale - deutsche Version. Unveröffentlichtes Manuskript. Universität Münster; 2013.

58. Ravens-Sieberer U, Erhart M, Rajmil L, Herdman M, Auquier P, Bruil J, et al. Reliability, construct and criterion validity of the KIDSCREEN-10 score: a short measure for children and adolescents' well-being and health-related quality of life. Qual Life Res. 2010;19(10):1487-500. https://doi.org/10.1007/ s11136-010-9706-5.

59. Bourdon KH, Goodman R, Rae DS, Simpson G, Koretz DS. The strengths and difficulties questionnaire: U.S. normative data and psychometric properties. J Am Acad Child Adolesc Psychiatry. 2005;44(6):557-64. https://doi.org/10. 1097/01.chi.0000159157.57075.c8.

60. Woerner W, Becker A, Friedrich C, Rothenberger A, Klasen H, Goodman R. Normierung und Evaluation der deutschen Elternversion des 
Strengths and Difficulties Questionnaire (SDQ): Ergebnisse einer repräsentativen Felderhebung. Zeitschrift Fur Kinder-und

Jugendpsychiatrie Und Psychotherapie - Z Kinder Jugendpsychiat Psych. 2002;30:105-12. https://doi.org/10.1024//1422-4917.30.2.105.

61. Becker A, Wang B, Kunze B, Otto C, Schlack R, Hölling H, et al. Normative data of the self-report version of the German strengths and difficulties questionnaire in an epidemiological setting. Z Kinder Jugendpsychiat Psych. 2018;46:523-33. https://doi.org/10.1024/1422-4917/a000589.

62. Nikolaidis A, Paksarian D, Alexander L, DeRosa J, Dunn J, Nielson DM, et al. The Coronavirus Health and Impact Survey (CRISIS) reveals reproducible correlates of pandemic-related mood states across the Atlantic. medRxiv. 2020:2020.08.24.20181123. https://doi.org/10.1101/ 2020.08.24.20181123.

63. Lenz B, Mühle C, Braun B, Weinland C, Bouna-Pyrrou P, Behrens J, et al. Prenatal and adult androgen activities in alcohol dependence. Acta Psychiatr Scand. 2017;136(1):96-107. https://doi.org/10.1111/acps.12725.

64. Lenz B, Müller CP, Stoessel C, Sperling W, Biermann T, Hillemacher T, et al. Sex hormone activity in alcohol addiction: integrating organizational and activational effects. Prog Neurobiol. 2012;96(1):13663. https://doi.org/10.1016/j.pneurobio.2011.11.001.

65. Kornhuber J, Erhard G, Lenz B, Kraus T, Sperling W, Bayerlein K, et al. Low digit ratio 2D:4D in alcohol dependent patients. PLoS One. 2011;6(4):e19332. https://doi.org/10.1371/journal.pone.0019332.

66. Huber SE, Zoicas I, Reichel M, Mühle C, Büttner C, Ekici AB, et al. Prenatal androgen receptor activation determines adult alcohol and water drinking in a sex-specific way. Addict Biol. 2018;23(3):904-20. https://doi.org/10.1111/ adb. 12540.

67. Neyse L, Ring P, Bosworth SJ. Prenatal testosterone exposure predicts mindfulness: does this mediate its effect on happiness? 2015.

68. Fink B, Neave N, Manning JT. Second to fourth digit ratio, body mass index, waist-to-hip ratio, and waist-to-chest ratio: their relationships in heterosexual men and women. Ann Hum Biol. 2003;30(6):728-38. https:// doi.org/10.1080/03014460310001620153.

69. Singh NN, Lancioni GE, Myers RE, Karazsia BT, Winton ASW, Singh J. A randomized controlled trial of a mindfulness-based smoking cessation program for individuals with mild intellectual disability. Int J Ment Heal Addict. 2014;12(2):153-68. https://doi.org/10.1007/s11469-013-9471-0.

\section{Publisher's Note}

Springer Nature remains neutral with regard to jurisdictional claims in published maps and institutional affiliations.

Ready to submit your research? Choose BMC and benefit from:

- fast, convenient online submission

- thorough peer review by experienced researchers in your field

- rapid publication on acceptance

- support for research data, including large and complex data types

- gold Open Access which fosters wider collaboration and increased citations

- maximum visibility for your research: over $100 \mathrm{M}$ website views per year

At $\mathrm{BMC}$, research is always in progress.

Learn more biomedcentral.com/submissions 